\title{
PENGARUH KOMUNIKASI DOKTER TERHADAP KESEMBUHAN PASIEN RAWAT JALAN
}

\author{
Gunawan Saleh dan Muhammad David Hendra \\ gunawan.saleh@univrab.ac.id \\ Program Studi Ilmu Komunikasi, Universitas Abdurrab
}

\begin{tabular}{l}
\hline Article Info \\
\hline Keyword: \\
Komunikasi Kesehatan, Dokter, \\
Pasien
\end{tabular}

\begin{abstract}
A well constructed communications between doctorand patient is one of the keys to su ccessful doctorsin providing medical service efforts. Unsuccessfuldoctor medical prob lems if communicated well willnot give rise to a dispute, but rather a medicalsuccess achieved whatsoever if it is notcommunicated, and patients feel not satisfied canalso $g$ ive rise to disputes or medical disputes.

In the profession of medicine communicationbetween doctors and patients is the mosti mportant component and is important in giving thewaiter points towards the patient. The effectivenessof communication between doctor and patient willcreate success in $t$ he process of patient care,treatment given aims to improve the health statusof the pati ent.

Health communication include the utilization ofservices of communication to convey messages andinfluence the decision making process related tohealth management and enhancement efforts byindividuals and community. In addition, it alsoincludes health communication activitiesdisseminate information about health to thecommunity in ord er to be achieved conduct healthyliving, creating awareness, change attitudes andmot ivate individuals to adopt the recommendedhealthy behaviors become the main purpo se of health communication.
\end{abstract}

Copyright (C) 2019 Interaksi: Jurnal Ilmu Komunikasi. All rights reserved.

\section{PENDAHULUAN}

Komunikasi kesehatan mencakup pemanfaatan jasa komunikasi untuk menyampaikan pesan dan mempengaruhi proses pengambilan keputusan yang berhubungan dengan upaya peningkatan dan pengelolaan kesehatan oleh individu maupun komunitas masyarakat. Selain itu, komunikasi kesehatan juga meliputi kegiatan menyebarluaskan informasi tentang kesehatan kepada masyarakat agar tercapai perilaku hidup sehat, menciptakan kesadaran, mengubah sikap dan memberikan motivasi pada individu untuk mengadopsi perilaku sehat yang direkomendasikan menjadi tujuan utama komunikasi kesehatan.

Komunikasi kesehatan memberi kontribusi dan menjadi bagian dari upaya pencegahan penyakit serta promosi kesehatan. Komunikasi kesehatan juga dianggap relevan dengan beberapa konteks dalam bidang kesehatan, termasuk didalamnya 1) hubungan antara ahli medis dengan pasien, 2) daya jangkau individu dalam mengakses serta memanfaatkan informasi kesehatan, 3) kepatuhan individu pada proses pengobatan yang harus dijalani serta kepatuhan dalam melakukan saran medis yang diterima, 4) bentuk penyampaian pesan kesehatan dan kampanye kesehatan 5) penyebaran informasi mengenai resiko kesehatan pada individu dan populasi, 6) gambaran secara garis besar profil kesehatan di media massa dan budaya, 7) pendidikan bagi pengguna jasa kesehatan bagaimana mengakses fasilitas kesehatan umum serta sistem kesehatan dan 8) perkembangan aplikasi program seperti tele- kesehatan. (Rahmadiana, 2012). 
Pada rencana penelitian ini akan melihat Pengarih Komunikasi dokter dalam kesembuhan pasien rawat jalan. Hal yang paling mendasar dari penelitian ini adalah ingin melihat hubungan kedua variabel tersebut. Menurut asumsi penulis, banyak pasien kurang puas untuk berkonsultasi secara bebas dan leluasa. Dokter juga terkesan tergesa-gesa seakan mengejar target terhadap kuantitas pasien kontrol. Sementara itu asumsi penulis juga bahwa selain pengobatan medis, sugesti dari dokter juga poin penting dalam mencapai kesembuhan pasien. Hal ini disebut juga sebagai komunikasi kesehatan.

Melihat penelitian-penelitian terdahulu yang menjadi acuan peneliti :

Pertama, Arianto 2012 Hasil yang didapat adalah bahwa komunikasi kesehatan memiliki dampak positif, penentu utama kepuasan pasien dan kepatuhan terhadap pengobatan dan perawatan.Bentuk-bentuk komunikasi kesehatan secara eksplisit dilakukan melalui komunikasi interpersonal dengan bentuk-bentuk keramahan dokter, perilaku sopan, percakapan sosial, perilaku mendorong dan empatik, membangun kemitraan dan ekspresi empati selama komunikasi.

Kedua, Penelitian yang dilakukan oleh Tita Menawati Liansyah dan Hendra Kurniawan, dimana mereka meneliti tentang pentingnya komunikasi dalam pelayanan kesehatan primer.Dalam penelitiannya, diperoleh informasi bahwa dalam profesi kedokteran, komunikasi antara dokter dan pasien merupakan komponen paling penting. Hubungan interpersonal yang baik antara dokter dan pasien dapat dilihat sebagai tujuan penting komunikasi. Pentingnya informasi yang disampaikan dari dokter ke pasien meliputi dari prosedur penyembuhan yang akan dilakukan, resiko yang mungkin terjadi, manfaat dari tidakan yang akan dilakukan, dan alternatif dari tindakan yang dapat dilakukan.

Ketiga, Penelitian yang dilakukan oleh Hikmah Hadiati Salisah, di mana hasil penelitiannya menjelaskan bahwa tidak diragukan lagi bahwa ilmu komunikasi bersifat omnipresent, dapat ditemukan di segala bidang kehidupan. Meski dimasukkan dalam kelompok ilmu sosial, ternyata juga menunjukkan diri sebagai ilmu yang bisa ditemukan bahkan dalam ilmu eksakta sekalipun, seperti bidang kesehatan individu dengan demikian menjadi sebuah keniscayaan bagi ilmu komunikasi untuk terus dikembangkan dengan menggunakan perspektif multidisipline.

\section{KAJIAN PUSTAKA}

\section{Metodologi}

Berdasarkan problem penelitian yang sudah dijelaskan sebelumnya, maka penelitian ini lebih tepatnya menggunakan multi metode atau dengan pendekatan kuantitatif, yakni dengan metode survei dilakukan untuk melihat praktik komunikasi kesehatan (dokter-pasien) sebagai pengobatan non-medis di Pekanbaru. Dalam menentukan sampel Menurut Sugiyono (2010:91) ukuran sampel yang layak dalam penelitian adalah antara 30 sampai dengan 500. Jika dilihat pada perhitungan di atas, maka sampel dalam peneltitian ini ditetapkan sebanyak 100 orang. Hal tersebut sudah layak untuk dijadikan sampel dalam penelitian ini. Kemudian, teknik pengambilan sampel yang digunakan dalam penelitian ini adalah nonprobability sampling. nonprobability sampling yaitu teknik pengambilan sampel yang tidak memberikan peluang/kesempatan sama bagi setiap unsur atau anggota populasi untuk dipilih menjadi sampel.

Secara khusus pengambilan sampel menggunakan teknik sampling insidental, yaitu teknik penentuan sampel berdasarkan kebetulan, yaitu siapa saja yang secara kebetulan/insidental bertemu dengan peneliti dapat digunakan sebagai sampel, bila dipandang orang yang kebetulan ditemui itu cocok sebagai sumber data. Sampel dalam penelitian ini ditetapkan sebanyak 100 orang pasien. Cara pengambilan sampel ini menggunakan teknik insidental sampling yaitu siapa saja yang ditemukan pada saat penyebaran kuesioner.

Analisis data yang digunakan dalam penelitian ini adalah analisis kuantitatif. Analisis kuantitatif menggunakan alat analisis bersifat kuantitatif yaitu alat analisis yang menggunakan model-model seperti model matematika (seperti fungsi multivariant), model statistik, dan ekonometrik dengan menggunakan alat bantuhitung SPSS. Analisis data dalam penelitian ini 
adalah analisis frekuensi olahan data dengan SPSS yang berasal dari angket yang disebarkan kepada pasien, namun sebelum melakukan analisis terhadap efektivitas komunikasi kesehatan terlebih dahulu dilakukan analisis terhadap validitas dan reliabilitas perangkat pengumpulan data (kuesioner/angket).

\section{Kajian Konseptual}

Di Indonesia sendiri dinyatakan dalam UU Nomor 23 tahun 1992 tentang Kesehatan bahwa kesehatan adalah keadaan sejahtera dari badan, jiwa dan sosial yang memungkinkan hidup produktif secara sosial dan ekonomi. Dalam pengertian ini maka kesehatan harus dilihat sebagai satu kesatuan yang utuh

Berdasarkan beberapa pengertian di atas tersebut menjadi sangat jelas bahwa konsep kesehatan sesungguhnya tidak mutlak hanya bicara faktor klinis atau medis melainkan juga faktor non klinis/ medis. Faktor ini dapat terjadi melalui komunikasi dokter dan pasien (kesehatan). Penekanannya berada pada bentuk komunikasi interpersonal yang dilakukan di antara keduanya.

\section{Komunikasi Dokter dan Pasien}

Dalam studi komunikasi kesehatan dapat ditemukan adanya pondasi teoretis pemikiran yang mengelompok dalam beberapa pendekatan, yaitu positivistik, interpretif, kritis dan pendekatan budaya. Jelas bahwa solusi masalah kesehatan individu bukan sekedar memperbaiki masalah kerusakan fisik seperti pada pendekatan biomedis tetapi juga dalam banyak kasus kesehatan ternyata melibatkan kompleksitas kebutuhan, motivasi dan prioritas individu.

Adanya sifat subyektifitas konsep sakit ini menjadi peluang bagi masuknya kajian berdasarkan perspektif ilmu komunikasi, khususnya jika menggunakan batasan komunikasi intrapersonal sebagai proses individu dalam menggali caracara yang di dalamnya pemaknaan kesehatan dinyatakan, diinterpretasi dan dipertukarkan, sebuah proses investigasi interaksi dan strukturasi simbolik dalam diri sendiri yang dikaitkan dengan kesehatan (Salisah, 2011: 175).
Komunikasi kesehatan mengarah pada jalannya proses komunikasi dan pesan yang menyelimuti isu kesehatan. Pengetahuan dalam bidang ini dapat dikategorikan berdasarkan penekanannya ke dalam dua kelompok besar yaitu perspektif berdasarkan proses dan perspektif berdasarkan pesan. Pendekatan berdasarkan proses menggali cara-cara yang di dalamnya pemaknaan kesehatan dinyatakan, diinterpretasi dan dipertukarkan, sebuah proses investigasi interaksi dan strukturasi simbolik yang dikaitkan dengan kesehatan, sedangkan perspektif berbasis pesan terpusat pada pembentukan pesan kesehatan yang efektif, juga mengenai usaha strategis untuk menciptakan komunikasi yang efektif yang dapat mencapai tujuan para stakeholders bidang kesehatan (Salisah, 2011: 170)

Komunikasi kesehatan merupakan bagian dari komunikasi antar manusia yang memiliki fokus pada bagaimana seorang individu dalam suatu kelompok/masyarakat menghadapi isu-isu yang berhubungan dengan kesehatan serta berupaya untuk memelihara kesehatannya. Fokus utama dalam komunikasi kesehatan adalah terjadinya transaksi yang secara spesifik berhubungan dengan isuisu kesehatan dan faktor faktor yang mempengaruhi transaksi tersebut (Rahmadiana, 2012: 88).

Kemampuan seorang dokter untuk memiliki keterampilan berkomunikasi dengan baik terhadap pasiennya untuk mencapai sejumlah tujuan yang berbeda. Ada 3 (tiga) tujuan yang berbeda komunikasi antara dokter dan pasien, yaitu :

1.Menciptakan hubungan interpersonal yang

baik (creating a good interpersonal relationship)

2.Pertukaran informasi (exchange of information)

3.Pengambilan keputusan medis (medical decision making) (Arianto, 2012)

Komunikasi dalam lingkup kesehatan begitu penting. Hasil konferensi tentang komunikasi kesehatan yang berlangsung di Toronto menghasilkan 'Toronto Consensus", menghasilkan 8 (delapan) point pernyataan hubungan antara praktek komunikasi dan kesehatan sebagai berikut : 
1) Communication problems in medical practice are important and common.

2) Patient anxiety and dissatisfaction are related to uncertainty and lack of information, explanation and feedback.

3) Doctors often misperceive the amount and type of information that patients want to receive.

4) Improved quality of clinical communication is related to positive health outcomes.

5) Explaining and understanding patient concerns, even when they cannot be resolved, results in a fall in anxiety.

6) Greater participation by the patient in the encounter improves satisfaction, compliance and treatment outcomes

7) The level of psychological distress in patients with serious illness is less when they perceive themselves to have received adequate information.

8) Beneficial clinical communication is routinely possible in clinical practice and can be achieved during normal clinical encounters, without unduly prolonging them, provided that the clinician has learned the relevant techniques (Arianto, 2012: 5)

Kemampuan interpersonal oleh dokter kepada pasiennya memiliki hubungan signifikan dalam upaya kesembuhan pasien Seorang praktisi kesehatan yang berusaha untuk membentuk hubungan baik dan hubungan persahabatan dengan pasien serta meyakinkan mereka bahwa mereka akan segera menjadi lebih baik, lebih efektif daripada praktisi kesehatan yang terus- menerus berkonsultasi secara impersonal (tidak akrab dan tidak bersahabat), formal atau tidak pasti (Arianto, 2012).

Bentuk hubungan Komunikasi antara dokter dan pasien ditekankan pada terjadinya komunikasi efektif antara dokter dan pasien yang memberikan manfaat. Edelmann mengidentifikasi empat faktor utama yang mungkin mempengaruhi sifat dan efektivitas komunikasi antara dokter dan pasien, yaitu sebagai berikut :

1. Karakteristik dokter (jenis kelamin dan pengalaman).

2. Karakteristik pasien (jenis kelamin, kelas sosial, usia, pendidikan dan keinginan akan informasi)

3. Perbedaan antara kedua belah pihak dalam hal kelas sosial dan pendidikan sikap, keyakinan dan harapan.

4. Faktor-faktor situasional atau beban pasien, tingkat kenalan dan sifat masalah yang diajukan (Arianto, 2012).

Komunikasi kesehatan yang efektif harus dilaksanakan dengan perencanaan yang matang. Menurut Parvanta dkk (2011), perencanaan komunikasi kesehatan terdiri dari 6 tahapan yaitu perencanaan makro, perencanaan strategi komunikasi, perencanaan implementasi/ taktis, perencanaan evaluasi, perencanaan keberlangsungan program, dan bila diperlukan perencanaan publikasi.

Tahap pertama adalah perencanaan makro meliputi analisis permasalahan kesehatan, menentukan model ekologis, strategi intervensi, dan penentuan populasi target (audiens). Perencanaan ini dapat dilakukan bila data-data epidemiologik menunjukkan terdapat permasalahan yang mempengaruhi kesehatan kelompok / komunitas. Bila ternyata pada komunitas tersebut telah ada intervensi yang pernah dilakukan, maka intervensi yang diusulkan agar diuji terlebih dahulu. Pada tahapan ini, minimal output perencanaan yang dihasilkan adalah diketahuinya permasalahan atau potensi permasalahan yang ada, sebelum masuk ke tahap perencanaan berikutnya.

Tahap kedua yaitu perencanaan strategi komunikasi. Pada tahap ini perencanaan difokuskan pada tujuan khusus perubahan perilaku, jenis audiens yang akan diintervensi, pesan-pesan yang akan disampaikan, dan media yang akan digunakan. Disamping itu dilakukan pengujian (uji coba) terhadap strategi konsep, pesan, materi, dan media yang akan dipakai. Terkadang dibutuhkan riset yang mendalam terhadap strategi yang akan dipakai.

Tahap ketiga adalah perencanaan implementasi atau perencanaan taktis, yaitu 
merencanakan pelaksanaan komunikasi kesehatan secara taktis dan teknis. Pada tahap perencanaan ini setidaknya ada enam jenis pertanyaan yang harus dijawab yakni Apa yang akan dilakukan? Dimana dilakukannya? Kapan dilakukan? Bagaimana cara melakukannya? Dengan anggaran berapa? dan Siapa yang bertanggung jawab?

Tahap keempat adalah perencanaan evaluasi yaitu merencanakan metode untuk menilai keberhasilan program komunikasi kesehatan. Pada tahap ini perencanaan difokuskan pada penentuan aspek/dimensi untuk memonitor dan mengevaluasi intervensi komunikasi kesehatan. Tujuan dari perencanaan ini adalah memastikan kemanfaatan program komkes bagi pemangku kepentingan. Sebaiknya perencanaan evaluasi dilakukan di awal pelaksanaan.

Tahap kelima adalah perencanaan keberlangsungan program komkes. Pada tahap ini ditentukan atau direncanakan kegiatan untuk menjalin kerjasama dan kemungkinan pengembangan program komkes agar tetap berkesinambungan. Adapun tujuan dari perencanaan ini adalah:

a) Memastikan bahwa program komkes menjangkau audiesn yang luas.

b) Mengurangi biaya.

c) Menghasilkan program yang berkelanjutan.

Tahap terakhir adalah perencanaan publikasi. Tahap ini dilakukan bila memang dibutuhkan publikasi atau penyampaian hasil kegiatan kepada pihak- pihak terkait, pemangku kepentingan dan masyarakat luas. Media publikasi yang dipilih sebaiknya sesuai dengan karakteristik audiens.

Untuk memberikan kemudahan kepada penulis maupun pembaca, perlu penulis menggambarkan skema atau alur berfikir dari penelitian ini, maka penulis membuat suatu rancangan kerangka pemikiran sebagai berikut :

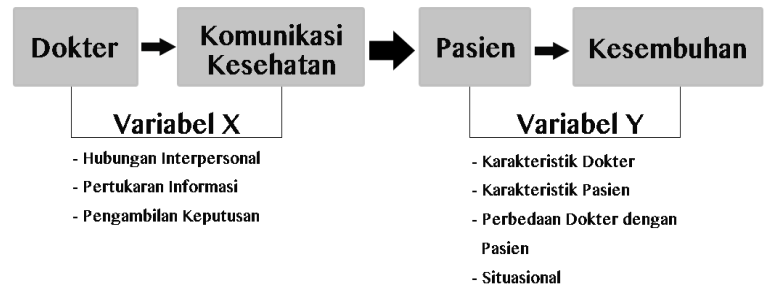

\section{TEMUAN DAN DISKUSI}

Variabel Bebas

\begin{tabular}{|c|c|}
\hline Dimensi & Indikator \\
\hline \multirow{3}{*}{$\begin{array}{l}\text { Hubungan Inter- } \\
\text { personal }\end{array}$} & Mengenal dokter \\
\hline & Pengalaman dokter \\
\hline & Kenyamanan \\
\hline \multirow{3}{*}{$\begin{array}{l}\text { Pertukaran Infor- } \\
\text { masi }\end{array}$} & Kejelasan bahasa \\
\hline & Komunikasi nonverbal \\
\hline & Media yang digunakan \\
\hline Pengambilan & Pemahaman pasien Kesepa \\
\hline Keputusan & $\begin{array}{l}\text { katan antara dokter dan } \\
\text { pasien }\end{array}$ \\
\hline
\end{tabular}

Variabel Terikat (Dependent Variabel)

Variabel terikat dalam penelitian ini adalah bagaimana efektifitas komunikasi antara dokter dan pasien diantaranya karakteristik dokter (jenis kelamin dan pengalaman), karakteristik pasien (jenis kelamin, kelas sosial, usia, pendidikan dan keinginan akan informasi), perbedaan antara kedua belah pihak dalam hal kelas sosial dan pendidikan sikap, keyakinan dan harapan dan yang terkahir faktor-faktor situasional (beban pasien, tingkat kenalan dan sifat masalah yang diajukan).

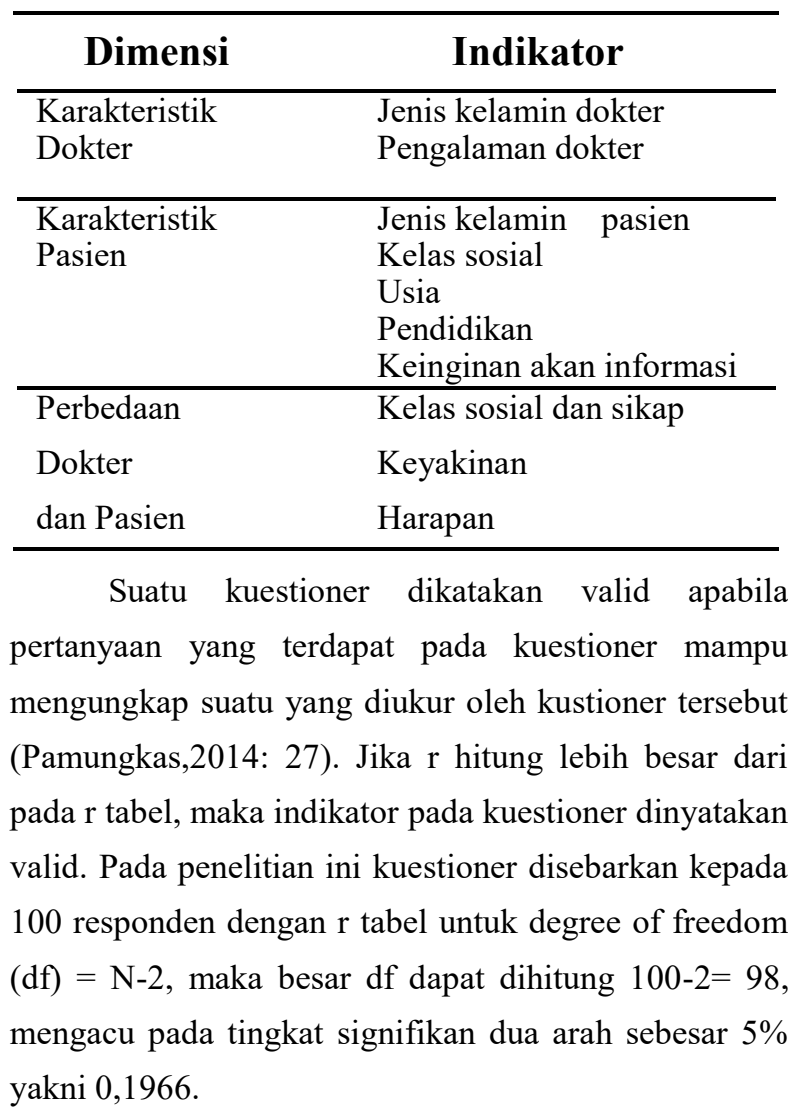


Berdasarkan uji validitas pada maka didapat tiga indikator Tidak Valid dikarenakan nilai $r$ hitung lebih kecil dari 0,1966. Dalam uji reliabilitas menurut Malhotra dalam (Suparno, 2009) Apabila nilai dari alpha lebih besar dari 0,50 maka instrumen dalam penelitian ini dianggap reliabel. Maka dari tabel diatas dapat dilihat bahwa variabel dalam penelitian ini dianggap reliabel

\section{Reliability Statistics}

\begin{tabular}{|r|r|}
\hline $\begin{array}{c}\text { Cronbach's } \\
\text { Alpha }\end{array}$ & N of Items \\
\hline .707 & 14 \\
\hline
\end{tabular}

\section{KESIMPULAN}

Setelah dilakukan kajian penelitian kuantitatif tentang pengaruh komunikasi dokter terhadap kesembuhan pasien rawat jalan, dimana variabel independent yaitu komunikasi dokter dan variabel dependent yaitu kesembuhan pasien. Maka hasil dari penelitian yang menunjukan bahwa komunikasi dokter secara signifikan memiliki pengaruh terhadap kesemnbuhan pasien rawat jalan. Apabila seorang dokter memiliki hubungan interpesonal yang baik, pertukaran informasi yang baik dan pengambilan keputusan yang baik maka akan semakin tinggi tingkat kesembuhan pasien (perbedaan dokter antara pasien dan faktor situasional) rawat jalan.

\section{DAFTAR PUSTAKA}

Ali, Mulyohadi \& Poernomo, Ieda Sigit Sidi. (2006); Komunikasi Efektif Dokter - Pasien. Konsil Kedokteran Indonesia. Jakarta

Arianto, (2012). Komunikasi Kesehatan (Komunikasi Antara Dokter dan Pasien). Palu: Universitas Tadulako

Fourianalistyawati, Endang (2012). Komunikasi Yang Relevan Dan Efektif Antara Dokter Dan Pasien, Jurnal Psikogenesis. Vol. 1, No. 1 edisi Desember. Universitas YARSI.

Menawati, TL \& Kurniawan, H, (2015) Pentingnya Komunikasi Dalam Pelayanan Kesehatan Primer. Jurnal Kedokteran Syiah Kuala Volume 15 Nomor 2.
Pamungkas, S. L. (2014). Analisis Pengaruh Kepercayaan dan Komitmen Terhadap Kesetiaan Mahasiswa Tahun Pertama Perguruan Tinggi Swasta Di Jakarta. Jakarta: Fakultas Ekonomi dan Ilmu Sosial Universitas Bakrie.

Parvanta, C., David E.N., Sarah A.P., dan Richard N.H. (2011). Essentials of Public Health Ontario: John \& Bartlet Learning

Rahmadiana, Metta (2012). Komunikasi Kesehatan, Sebuah Tinjauan. Jurnal Psikogenesis, Vol. 1, No.1.

Salisah, Nikmah Hadiati. (2011). Komunikasi Kesehatan: Perlunya Multidisipliner Dalam Ilmu Komunikasi. Jurnal Ilmu komunikasi, Vol. 1, No. 2.

Sugiyono. 2010, Statistika untuk Penelitian. Bandung: Alfabeta.

Suparno. (2009). Persepsi Mahasiswa Fakultas Ekonomi Universitas Syiah Kuala Terhadap Perbankan Syariah Berbagai Lembaga Keuangan Syariah. Jurnal Telaah \& Riset Akuntansi, 93-103.

UU No.23 Tahun 1992 Tentang Kesehatan 